\title{
Cultural Challenges Facing East Asian Higher Education: A Preliminary Assessment
}

\author{
Rui Yang \\ yangrui@hku.hk
}

Higher education development has been achieving highly in major East Asian societies including China, Japan, Korea, Hong Kong and Taiwan. The achievement becomes even more remarkable when compared with other non-Western societies. East Asian societies aspire openly to elevating some of their universities to world-class status. While East Asia's achievement in higher education has been widely agreed, assessment of its future development is not. To some, East Asian universities are challenging Western supremacy and gradually eclipsing the Western university system. To others, East Asian universities generally lag behind the best universities in the West. While both views cite culture as the reason, neither of them is cultural enough. Although there is an evident pride of the idea that East Asian universities are not willing to assume that Western models define excellence, few are able to theorize East Asia's differences from Western universities. Questions remain about the true potential of Asia's universities and whether they can truly break the Western hegemony. This paper problematizes the strikingly different and even opposite assessments of higher education development in East Asia. It historicizes East Asian higher education and raises questions about the perceived shift of the center of gravity in higher education to Asia. Based on the author's longstanding professional observation, it assesses East Asia's higher education development to attest Altbach's judgment that a kind of "glass ceiling" is to be reached soon by East Asian universities.

\section{Biography}

Rui Yang is Professor of Education at the University of Hong Kong. With 26 years of academic career in China, Australia and Hong Kong, he has an impressive track record on research at the interface of Chinese and Western traditions in education. He has established his reputation among scholars in English and Chinese national languages in the fields of comparative and international education and Chinese higher education. Bridging the theoretical thrust of comparative education and the applied nature of international education, his research interests include comparative and cross-cultural studies in education, international higher education, and education policy sociology. 